request for help to die. Though I recognise that there are two sides to this argument, the remarks made by Dr Horner can only obscure the real issues. Therefore the opportunity to address people's real concerns was lost.

JOHN OLIVER

Voluntary Euthanasia Society-Exit, London W8 5PG

1 Legalised euthanasia is categorically rejected. $B M \mathcal{f}^{7} 1993 ; 307$ : 132-3. (10 July.)

\section{Smoking and risk of cardiovascular disease}

EDrToR,-Eva Negri and colleagues' conclusion that changing to cigarettes with a lower tar yield is not an effective means of reducing morbidity from myocardial infarction related to tobacco cannot be drawn from their study: they offer no data to support this conclusion. ${ }^{1}$ The reasons for a person choosing low or high tar cigarettes need to be addressed: possibly those who prefer low tar cigarettes are already at greater risk of cardiovascular disease for either genetic or lifestyle reasons. The only conclusion that should be drawn from the study is that smokers of cigarettes with different tar yields have comparable risks of myocardial infarction.

MJO'DONNELL

Manor Hospital,

Walsall WS2 9PS

1 Negri E, Franzoni MG, La Vechia C, Santoro L, Nobili A, Tagnoni G. Tar yields of cigarettes and risk of acute myocardial infarction. $B M F$ 1993;306:1567-70. (12 June.)

\section{Chronic fatigue syndrome}

EDITOR,-In P K Thomas's succinct review of chronic fatigue syndrome, the extensive morbidity, misery, and misinformation that exists around this subject is not stated. ${ }^{1}$ The present situation is also not helped by the majority of medical practitioners having no education in, and little experience of, managing this common disorder.

Irrespective of the cause or the emotional response this syndrome produces in professionals, it creates considerable disability in our communities. The overall prevalence of people who suffer with intrusive fatigue is estimated at $150000 .^{2}$ Many of these (as yet unmeasured) are debilitated to such an extent that they are unable to work and are dependent on carers. It is interesting to note that within the NHS there is at the moment no single unit dedicated or equipped to assess, treat, and provide long term support for such patients. Limited facilities have been provided in beds that are earmarked for other disorders.

It is generally accepted that nothing positive can be done to help these patients, and this attitude is adopted by many doctors, who see their role as making a diagnosis without offering follow up treatment or support. The symptom complexes of these patients are wide ranging and include sleep disturbances, muscle pain, depression, emotional lability, and gastrointestinal disturbances. All these symptoms can be treated, even when there may be doubt that anything can influence the core problem.

It is apparent from our experience working with people with chronic fatigue syndrome that there are psychological components that must be identified and treated and which can respond to a combined approach to treatment that takes into account the complex of symptoms. The basic philosophy is that the illness is a real and manageable condition and one from which patients can recover given the right information, management, and treatment techniques to work with. We are using a combination of graded activity, cognitive behaviour therapy, and drugs. ${ }^{3}$ Drugs used alone, without modification and adaptation of lifestyle to promote recovery, are invariably unsuccessful.

Much can and should be done to help these patients. To that end the National Charity for Chronic Fatigue Syndrome (commonly called myalgic encephalomyelitis (ME)) has been set up at Harold Wood Hospital, Romford, to provide facilities and support. The ultimate aim is to provide both inpatient and outpatient services for people with fatigue syndromes of all types, regardless of the conductive mechanism, which may be left to a future generation of doctors to unravel.

DIANE L COX

Department of Neurology,

ESLIE J FINDLEY

Romford, Essex RM7 0BE

1 Thomas PK. The chronic fatigue syndrome: what do we know? $B M 7$ 1993;306:1557-8.

Wallace PG. Epidemiology: a critical review. $B r$ Med Bull 1991:47:942-51.

3 Cox DL, Findley LJ. Is chronic fatigue syndrome treatable in an NHS environment? Clin Rehab (in press).

\section{Triazolam}

EDrToR,-Recent letters and articles in the $B M \mathcal{F}$ continue to present inaccuracies regarding triazolam. Anthony Kales and colleagues erroneously state that 30 controlled studies confirm their assertions about the drug. ${ }^{1}$ They reference their petition to the United States Food and Drug Administration, which cited these studies but made faulty analyses, often misstating the origina authors' conclusions. Many of the cited studies had not, in fact, drawn negative conclusions regarding triazolam. ${ }^{2}$

Just a few months ago, when Kales et al published similarly unfounded statements in the Lancet, ${ }^{3}$ they claimed that over 100 published reports supported their assertions. We can only speculate why this number is now reduced to 30 . I have publicly noted that most of the "over 100 " reports were not clinical trials at all, and five were multiple publications of the same data by Kales and associates. $^{2}$

Kirstine Adam and Ian Oswald present a selective review of the Food and Drug Administration's assessment of Upjohn's clinical trial data. ${ }^{1}$ It bears repeating that the Food and Drug Administration reaffirmed that triazolam has an acceptable margin of safety. Adam and Oswald further assert the validity of Oswald's own study, although I am not aware of any other placebo controlled study replicating his claims of anxiogenic properties for triazolam and more than 20 published reports refute it. ${ }^{1}$ In addition to ignoring these older, nonsupportive data, Adam and Oswald ignore recen studies that also counter their claims.

Finally, in the light of the evidence that refutes an association of early morning insomnia and daytime anxiety with triazolam, it is surprising that this association is noted in Joel Eisen and colleagues' article on psychotrophic drugs and sleep. ${ }^{5}$ That such an assertion, which is not supported by most reports, was included in a review highlights the pernicious effect that unscientific accusations have on medical practice.

Upjohn Laboratories,

JEFFREY M JONAS

Kalamazoo,

MI 49001-0199,

USA

1 Correspondence. Triazolam. BMf 1993;306:1475-6. (29 May.) 2 Jonas JM. Adverse events after triazolam substitution. Lancet 1993;341:1150-1.

3 Kales A, Bixler EO, Vgontzas AN. Adverse events after triazolam substitution. Lancet 1993;341:567-8.
4 Pagot R, Cramer P, L'Heritier C, Coquelin J-P, Attali P. Comparison of the efficacy and tolerability of zolpidem $20 \mathrm{mg}$ and triazolam $0.5 \mathrm{mg}$ in anxious or depressed insomniac patients. Current Therapeutic Research 1993;53:88-97.

5 Eisen J, MacFarlane J, Shapiro CM. Psychotropic drugs and sleep. BMF 1993;306:1331-4. (15 May.)

\section{Community health doctors left out}

EDrToR,-I think that Linda Beecham, who wrote about the annual conference of public health medicine and community health, ${ }^{1}$ and I must have attended different conferences. I do not take issue with what was reported but am concerned at what was left out. For a start, the title of the article"From the public health conference"-ignores the fact that it was also the community health doctors' conference.

Some space in the article is devoted to the joint working party's report on medical services for children, a joint effort by doctors of several specialties including community health. Loretta Light, who chairs the community health subcommittee, is mentioned and pictured. Apart from this the considerable contribution of community health doctors and discussion of community health issues are not mentioned.

What happened to reporting of the motions on the damage to integrated child health services resulting from the NHS reforms? Or on the withdrawal of schools' health education coordinators? Or of family planning doctors' opposition to the proposed extension of the selected (limited) list to family planning supplies? Motions on all of these were passed, but none is reported. Nor is the discussion about whether public health medicine and community health should remain a single craft.

On this last point Beecham seems already to have decided. As a community health doctor I believe that we are being subtly written out of the script of medical politics.

Cockermouth

Cumbria CA13 OET

1 Beecham L. From the public health conference. BMF 1993;306: 1694-5. (19 June.)

\section{Authors have rights too}

EDrTOR,-Several articles have been published recently regarding the rights of authors with respect to their submission of papers to journals for publication. ${ }^{1-3}$ Many of the authors recount "torture at the hands of the editors" with regard to subsequent publication of articles. ${ }^{2}$ Chief concerns seem to be the length of time between an article being initially submitted and a final decision being made about its publication, the insulting tone of comments from referees, the authors being left feeling disheartened and angry about the way their article has been dealt with, and a feeling that many editorial boards of journals abuse their power.

It seems strange, therefore, that when readers subscribe to a journal and they themselves make the major contribution towards the content of the journal-purchasing, reading, and promoting the journal and of their own free accord refereeing articles for it-that they are then treated in what seems to be an unacceptable manner after they submit an article.

I suggest an author's ten point charter:

(1) Journals should publish the date they received the article and the date it was accepted, thereby allowing prospective authors to estimate the time delay in acceptance and publication.

(2) Authors have the right to request the editor 